\title{
Accepting premature deaths from smoking
}

W A Farone

\section{Could partial reduction of some toxic components in cigarettes lead to reductions in premature deaths from smoking?}

lstions one analyses the suggested means of solving the problem of premature death and disease caused by smoking, the strategies break down into four broad groups. Listed in the order in which I perceive these to have the highest probability of resulting in the most reduction in death to the least these are:

1) Smoking cessation

2) Replacement of the pharmacologic (pleasurable) sensations of nicotine in cigarette products with non-cigarette products that can be viewed as providing either medicinal nicotine or analogue chemicals with similar function

3) Reduction in toxic components of cigarette smoke immediately to levels that are suggested by current science as "acceptable" based on existing dose-response data for cumulative lifetime exposure. (This is a central part of the theme of the California Environmental Protection Agency's requirementsthat is, that there are levels of chemicals for which the risk is not more than "background".)

4) Partial reductions in some toxic components over time to eventually lead to products with reduced premature death rates

Should the last strategy be regarded as acceptable in light of the more definitive reductions in the other strategies? Is the reduced level of premature death hypothesised to follow a slow response to reducing toxicity for cigarettes something that should be supported?

\section{REDUCING NITROSAMINES}

In the paper by Gray and Boyle ${ }^{1}$ in this issue, a case is made for the reduction of one class of known carcinogen in cigarette smoke, the tobacco specific nitrosamines (TSNAs). They argue that the known global variations in TSNAs among cigarette brands are unacceptable and that the lowest levels able to be produced should be required. The fact that lower levels in some cigarettes have been achieved implies that all cigarettes could have the same lower levels.

Would there be any reduction in premature deaths if only TSNAs were reduced and, if so, would this reduction make such modified tobacco products more acceptable to current and future smokers? Or would a TSNA reduction derby lead to the same result as the tar reduction derby of the 1960s and 1970s - that is, no significant reduction in premature death rates. From the 1950s to about 1980 delivery levels of cigarettes in the USA experienced a reduction in the amount of chemicals delivered based on the standardised Federal Trade Commission test. This reduction was seen in the sales weighted "tar" average reported during the period. Today, these lower levels have been maintained, but not reduced further. The reductions were of the order of $70 \%$ over that period. Although there is the issue of smoker compensation in the lower delivery cigarettes, one might still have expected that the level of disease would have been significantly reduced based on the risk associated with exposure. For example, one might have expected that on average the risk would have dropped from that of a two pack a day smoker to that of a one pack a day smoker. Unfortunately dose-response curves are not linear. Further, the synergy of so many potent toxins was not considered. The combination of sufficient toxins and the dosing of the newer cigarettes created essentially the same disease rates.

\section{IMPLYING REDUCED RISK}

The manufacturers of cigarettes would like nothing better than to keep products on the market that are virtually unchanged from existing products. If the act of removing one toxin or even a few of the many toxins in cigarettes could be advertised as an achievement with the implications of reduced risk, more smokers may be deterred from quitting and more young non-smokers may feel reassured that the risk is small enough to begin smoking. This is directly analogous to the implicit advertising promise of the 1970s until today that lower tar cigarettes convey less risk.

There are several technologies that reduce TSNAs without reducing other toxic chemicals to any great extent. For example, the extraction technology used by Philip Morris in the denicotinised NEXT cigarette removes the bulk of the TSNAs along with the nicotinic alkaloids. ${ }^{2}$ In principle, replacing the alkaloids while leaving out the TSNAs would result in a great reduction in TSNAs, even more so than TSNA reduction resulting from improvements in the technology of curing tobacco. The TSNAs that would be delivered to a smoker would "only" be those that formed during the reactions of the alkaloids during the smoking and smoke aging process. A Philip Morris reference indicates that two thirds of the TSNA in Burley tobacco smoke and 33\% in Bright tobacco cigarette smoke is produced because of the high temperatures that occur during the burning of a cigarette, that is pyrosynthesised. ${ }^{2}$ In this case the amount in the cigarette tobacco itself can be misleading and the pyrosynthesised quantities are not eliminated by extraction or curing. Additional treatments, such as the removal of nitrosamine precursors like nitrate that produce nitric oxide, are needed.

Table 1 presents some of the information concerning levels of some of the carcinogenic materials in smoke considered to be "acceptable" based on a daily exposure value compared to a range of these chemicals reported in cigarette smoke on a "per cigarette" basis.

The list in table 1 is only for carcinogens and is a very limited selection chosen to make the specific point that many carcinogens are now being delivered at levels far in excess of reasonable levels. The number of cigarettes smoked per day will multiply the values in the "Amount in cigarettes" column. Eventually all of the carcinogens and teratogens on the California Proposition 65 list will have levels defined that are nominated as values of daily exposure that will increase risk by less than 1 in 100 000. These levels are a reasonable starting point but still do not take into account cumulative and synergistic effects.

\section{REGULATING LEVELS}

If such levels were regulated, the cigarette industry would no longer be able to argue as they do now that they are "trying to reduce levels". The levels of the chemicals and the risk associated with the levels would be defined. Levels that do not achieve some scientifically 
Table 1 Comparison of levels of some carcinogens in cigarette smoke

\begin{tabular}{lllll}
\hline Compound & $\begin{array}{l}\text { Safe harbour } \\
\text { level* }\end{array}$ & Units (per day) & $\begin{array}{l}\text { Amount in } \\
\text { cigarettes }\end{array}$ & $\begin{array}{l}\text { Units (per } \\
\text { cigarefte) }\end{array}$ \\
\hline $\begin{array}{l}\text { Acetaldehyde } \\
\text { Formaldehyde }\end{array}$ & 90 & Micrograms & $500-1400$ & Micrograms \\
Benzo(a)pyrene & 40 & Micrograms & $70-100$ & Micrograms \\
Benz(a)anthracene & 60 & Nanograms & $20-40$ & Nanograms \\
Dibenzo(a,l)pyrene & 40 & Nanograms & $20-70$ & Nanograms \\
4-(N-Nitrosomethylamino) & 14 & Nanograms & $1.7-3.2$ & Nanograms \\
-1-(3-pyridyl)1-butanone & & Nanograms & $80-770$ & Nanograms \\
Cadmium & 50 & Nanograms & $7-350$ & Nanograms \\
Chromium (hexavalent) & 1 & Nanogram & $4-70$ & Nanograms \\
Benzene & 7 & Micrograms & $20-70$ & Micrograms \\
Ethylene oxide & 2 & Micrograms & 7 & Micrograms \\
N-Nitrosodimethylamine & 40 & Nanograms & $2-180$ & Nanograms \\
\hline
\end{tabular}

*Data on safe harbour levels (levels of a chemical that are estimated to provide an increased risk of cancer of no more than 1 in 100 000) are from the California Environmental Protection Agency. ${ }^{3}$ Data on the amounts in cigarettes are from the National Cancer Institute: Risks associated cigarette with low machine-measured yields of tar and nicotine, Smoking and Control Monograph 13. ${ }^{4}$ objective reduced risk could not be used to encourage smoking. With respect to tar reductions, the cigarette industry argues today that public health authorities in the USA acknowledged the value of reduced tar cigarettes in the Surgeon General's reports of 1979 and 1981. Any study of the reduction of sales weighted tar in the USA will show that there have been no significant reductions since those reports were issued. When the cigarette industry achieved a small measure of presumed success they simply stopped reducing the tar further.

The result, of course, was that there were no significant reductions in the premature death rates due to "low tar" and "light" cigarettes as reported in the National Cancer Institute's Monograph 13. ${ }^{4}$ The levels in the column labelled "Amount in cigarettes" in table 1 is taken from those reported in chapter 5 of this monograph. The values were obtained during the period from 1980 to 1995 by various researchers and one may quibble with the ranges depending on the cigarettes and machine smoking regimen used. However, the levels in a single cigarette are so large compared to levels for daily acceptable exposure that the nuances of how one measures it are insignificant. One can see that the ranges for other chemicals are exceeded as much as they are exceeded for the specific TSNA listed (4(N-Nitrosomethylamino)-1-(3-pyridyl)1butanone), also called NNK. The ranges given in table 1 for this TSNA and for benzo(a)pyrene are also reported for various smoking regimens and different types of cigarettes in chapter 5 of Monograph $13 .{ }^{4}$

If we are going to advance solutions that allow smokers to continue to smoke, the smokers should not have to choose between risk levels of different chemicals. They should not have to believe that their cigarette is somehow better for them because a few of a wide range of carcinogens have been removed or reduced to some level that still cannot be shown to meet a reasonable standard for "no effect". Smokers should only be able to choose between products that are first proven to meet some exposure standard that will have a reasonable probability for dramatically reduced harm. After that standard is met the cigarette industry can determine how to make such products acceptable and compete in the marketplace if they still desire to do so.

\section{UNACCEPTABLE STRATEGY}

I submit that the strategy of focusing on a few chemicals and allowing partial reductions of some of these chemicals is not an acceptable strategy. It allows cigarette companies to continue to cause far too much premature death by lulling smokers into thinking it is acceptable to continue to take the smoking risk. Note that the chemicals listed are only relevant to cancer. Similar lists can be identified for heart disease and chronic obstructive pulmonary disease.

This does not mean we should allow the high levels of TSNA to continue. In fact the lowest levels possible should be insisted upon, as argued by Gray and Boyle. Those lowered levels should not be limited to TSNAs. Science in this area has the capability of nominating levels of all toxic compounds in smoke that should be a "maximum" allowed level. Since there is no intrinsic benefit to cigarettes that comes close to the risk involved, those nominated values can be conservative and subject to further revision as more information on the cumulative or synergistic effect of these chemicals becomes known. We do not need to wait to develop any more information to insist on the first three strategies.

Tobacco Control 2004;13:1-2. doi: 10.1136/tc.2004.007443

Correspondence to: W A Farone, PhD, Applied Power Concepts, Inc., 411 East Julianna Street, Anaheim, CA, 92801, USA; farone@appliedpowerconcepts.com

\section{REFERENCES}

1 Gray N, Boyle P. The case of the disappearing nitrosamines: a potentially global phenomenon? Tobacco Control 2004;13:13-16.

2 Philip Morris. Internal Document Bates Numbers 2024043504, 506-513, 526, 530, 532-534, $537-538,542-543,545,548-551,555-561$ 567-571, 577, 579-580. www.tobaccodocuments.com

3 California Environmental Protection Agency, Reproductive and Cancer Hazard Assessment Section, Office of Environmental Health Hazard Assessment. Proposition 65 status report, No significant risk levels for carcinogens and maximum allowable dose levels for chemicals causing reproductive toxicity. March 2002

4 National Cancer Institute. Risks associated cigarette with low machine-measured yields of tar and nicotine, Smoking and Control Monograph 13, Bethesda, Maryland: US Department of Health and Human Services, National Institutes of Health, National Cancer Institute, October 2001. (NIH Publication No.02-5074.) 